Journal of Accident and Emergency Medicine 1994

11, 105-108

Correspondence:

M.W. Cooke,

Consultant,

Accident and

Emergency

Department, City

Hospital, Dudley

Road, Birmingham

B18 7QH, UK

\title{
Audit of upper limb fracture management in an accident and emergency department
}

\author{
D.P. JENKINS, M.W. COOKE and E.E. GLUCKSMAN
}

Accident and Emergency Department, Kings College Hospital, Denmark Hill, London

\section{SUMMARY}

The objective of this study was to audit the initial management of patients with upper limb fractures, and to determine whether the accident and emergency (A\&E) management of fractures is improved by using guidelines for treatment and referral. This was achieved by comparing the standard of treatment, as determined by fracture clinic doctors, before and after the introduction of fracture treatment guidelines in the A\&E department of a London teaching hospital. A total of 326 patients seen in the department and referred to the fracture clinic over two 2-month periods were included in the audit. The first audit revealed some error in 69/215 $(32.1 \%)$ referrals and $51 / 215(23.7 \%)$ of these were potentially liable to increased morbidity. After introducing the guidelines the total errors fell to $14 / 111(12.6 \%)$ patients referred, of which only eight patients $(7.2 \%)$ were at risk of increased morbidity. This represents an overall improvement of $19.5 \%$ [95\% confidence interval $(\mathrm{Cl}) 12.3$ to $29.7 \%$ ] and a $16.5 \%(95 \% \mathrm{Cl} 9.1$ to $23.9 \%)$ reduction in the potentially more significant errors. Hence, the use of audit and implementation of simple guidelines for fracture management in an A\&E department improves the standard of treatment.

Key words: audit, emergency, fractures, guidelines, protocols

\section{INTRODUCTION}

The aim of medical audit is to assess, and eventually improve the quality of medical care. For audit to be meaningful, any improvements suggested by a given audit must be put into practice and a second audit completed to ensure beneficial change has occurred. ${ }^{1}$

Patients with upper limb fractures constitute a significant proportion of the workload of an A\&E department. In this paper we studied the management of patients who were seen by A\&E staff and referred to fracture clinic. The reasons for investigating this area include: relatively limited orthopaedic experience of most new A\&E senior house officers (SHOs); lack of 24-h on-site senior cover in the department; unavailability of 24-h immediate radiograph reporting; and the absence of a formal system for fracture clinic doctors to report management mistakes to A\&E SHOs. Feedback is important to identify the kind of mistakes that are being made, and how they can be minimized to improve the service to the patient and the education of the SHOs.

Most hospitals use guidelines to facilitate the safe and efficient investigation and treatment of patients with head injuries, but the use of similar systems for patients with more peripheral injuries is less widespread. Here we report the results obtained before and after using a set of management guidelines for upper limb fractures.

\section{METHODS}

In the first audit (January and February), a fracture clinic doctor completed a form for each patient who was seen with an upper limb fracture. Forms were reviewed by the A\&E registrar before being returned to the SHOs for teaching purposes.

The form allows the following information to be collected: doctor/patient identification; details of diagnosis; and treatment (reduction and method, type of plaster, type of sling) including the identity of the person applying/checking the plaster or performing the reduction. The form also permits the fracture clinic doctor to indicate whether or not the above were satisfactory, and whether the referral was appropriate with particular reference to radiograph interpretation, adequacy of treatment and management decision, and time interval.

After discussion of these results at an A\&E and orthopaedic audit meeting, management guidelines for common fractures were formulated and agreed by senior staff from both departments. These guide- 
Fig. 1. Page from guidelines covering hand fractures.

\begin{tabular}{|c|c|c|}
\hline \multicolumn{3}{|l|}{ Hand fractures } \\
\hline \multirow[t]{3}{*}{ Metacarpals: } & Undisplaced. & $\begin{array}{l}\text { Neighbour strap } \\
\text { fingers. Tubigrip and } \\
\text { high sling Clinic } \\
2-3 \text { days }\end{array}$ \\
\hline & Displaced/shortened/ & \\
\hline & Rotated/multiple rays . & $\begin{array}{l}\text { Discuss with ortho/ } \\
\text { A\&E reg. }\end{array}$ \\
\hline First metacarpal base & & $\begin{array}{l}\text { Reduce if necessary } \\
\text { Bennetts POP and } \\
\text { high sling Clinic } \\
2-3 \text { days }\end{array}$ \\
\hline Bennetts fracture dislocation & & Refer to ortho reg. \\
\hline MCP dislocations . . & & $\begin{array}{l}\text { Reduce and } \\
\text { neighbour strap } \\
\text { High sling Clinic } \\
1 \text { day }\end{array}$ \\
\hline \multirow[t]{4}{*}{ Gamekeepers thumb: } & $\begin{array}{l}\text { Undisplaced or no } \\
\text { fracture } \ldots \ldots \ldots\end{array}$ & $\begin{array}{l}\text { Scaphoid POP and } \\
\text { high sling }\end{array}$ \\
\hline & & Clinic 7 days \\
\hline & Displaced or rotated & Discuss with ortho/ \\
\hline & & A\&E reg. \\
\hline \multirow[t]{4}{*}{ Interphalangeal dislocations } & & Reduce and \\
\hline & & neighbour strap \\
\hline & & High sling Clinic \\
\hline & & $2-3$ days \\
\hline \multirow[t]{4}{*}{ Phalangeal fractures: } & Undisplaced....... & $\begin{array}{l}\text { Neighbour strap and } \\
\text { high sling }\end{array}$ \\
\hline & & Clinic 1 day \\
\hline & Displaced/angulated & \\
\hline & Intra-articular/compound & Refer to ortho reg. \\
\hline \multirow[t]{4}{*}{ Terminal phalan $x$} & 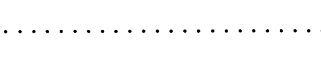 & $\begin{array}{l}\text { Mallet splint and } \\
\text { elevate }\end{array}$ \\
\hline & & Clinic 7 days \\
\hline & Compound. & Discuss with ortho/ \\
\hline & & A\&E reg. \\
\hline
\end{tabular}

lines were issued to new SHOs, and further copies were displayed in all clinical areas of the department. An example the page covering hand fractures can be seen in Fig. 1.

A second audit, was completed with the new SHOs using the agreed guidelines. The audit was conducted in exactly the same manner as the first and results were discussed at an audit meeting. In both sample periods, one of the 2 months related to new SHOs and none of the SHOs was involved in both stages of audit. The two groups of $10 \mathrm{SHOs}$ were at similar stages of their careers and had not had any previous A\&E experience or additional orthopaedic experience.

Statistical analysis of the two samples was carried out by calculating the Cls for the differences between two proportions (unpaired case), as described by Gardner \& Altman. ${ }^{2}$

\section{RESULTS}

Results for the first and second audit are compared in Table 1. More patients were seen in the first audit (215), compared with the second (111), which may have been the result of seasonal variation. Although the numbers were greater in the first audit, the case mix in each audit was not significantly different. Fractures of the distal radius, carpals and metacarpals constituted the largest groups; 127 (59\%) cases in the first audit and $56(51 \%)$ cases in the second. Fractures of the proximal radius and ulnar constituted the smallest groups; 21 (10\%) and 12 $(11 \%)$ respectively.

The total number of cases in which an error was found amounted to $69(32.1 \%)$ before the guidelines were introduced. A subset of 51 (23.7\%) patients were judged as liable to increased mor- 
Audit of upper limb

fracture
No. of patients

First audit (\%)

Second audit (\%)

\begin{tabular}{lcc}
\hline Diagnosis/outcome & $6(2.8)$ & $4(3.6)$ \\
Missed fracture & $7(3.2)$ & $3(2.7)$ \\
No fracture present & $3(1.4)$ & 0 \\
Reduction omitted & $3(1.4)$ & 0 \\
Reduction inadequate & $7(3.2)$ & $2(1.8)$ \\
Missed referral & $8(3.7)$ & 0 \\
Incorrect management & $27(12.6)$ & $3(2.7)$ \\
Plaster inadequate & $8(3.7)$ & $2(1.8)$ \\
Other treatment incorrect & & \\
& 215 & 111 \\
Total no. of patients & $51(23.7)$ & $8(7.2)$ \\
Total significant errors & $69(32.1)$ & $14(12.6)$ \\
Total errors & & \\
\hline
\end{tabular}

Table 1. Results of first and second audits bidity because of the errors. These errors included missed fractures, inadequate reduction of distal radius fractures, missed referral for treatment of phalangeal fractures, inadequate scaphoid plasters and delayed follow-up. After introduction of the guidelines, the number of cases where an error was made fell to $14(12.6 \%$ ), an improvement of $19.5 \%$, $(95 \% \mathrm{Cl} 12.3$ to $29.7 \%)$. The subset at risk of increased morbidity amounted to eight $\mathbf{( 7 . 2 \%}$ of the total), an improvement of $16.5 \%$, $(95 \% \mathrm{Cl} 9.1$ to $23.9 \%$ ).

The number of fractures missed by the A\&E department, but diagnosed at the fracture clinic attendance was six $(2.8 \%)$ in the first audit and four $(3.6 \%)$ in the second (not statistically significant). The patients who were referred to the clinic with the diagnosis of fracture, which was then unsubstantiated in the Fracture Clinic, were also not significantly different with seven $(3.2 \%)$ and three $(2.7 \%)$ patients respectively.

Missed referrals, (cases judged as being more suitably referred to the orthopaedic team on the day of presentation) amounted to seven (3.2\%) and two $(1.8 \%)$ patients respectively. In the first audit there were three $(1.4 \%)$ patients with an inadequate reduction and three $(1.4 \%)$ where reduction was not performed but should have been. No reduction errors were made in the second audit. Inadequate plasters were a common problem in the first audit with 27 $(12.6 \%)$ patients compared with three $(2.7 \%)$ in the later audit having inadequate plasters. Other treatment errors comprised incorrect splints and dressings.

The timing of fracture clinic appointment was judged to be inappropriate in four cases $(1.9 \%)$ in the first audit and in the second audit timing of appointments deviated from the suggested guidelines on $10(9.0 \%)$ occasions, but in no case was there any increased morbidity.

\section{DISCUSSION}

It has been stated that audit should lead to changes in the organization and availability of services, clinical policy and practice, with consequent improvement in the quality of medical care as measured by appropriate indicators. ${ }^{3}$ In this study, which forms part of our regular audit programme, we investigated an area of the work of the department and found where deficiencies occurred. After coming to an agreed practical solution to improve the service we re-audited to confirm that the solution worked.

The initial audit drew attention to the fact that in $33 \%$ of the cases seen in the department and referred to fracture clinic, there was a management error made (including diagnosis, use of reduction, adequacy of reduction, appropriateness of referral, type and standard of plaster, or type and standard of slings/splints/dressings). In particular the study highlighted the fact that many of the plasters, which are usually applied by medical students and checked by qualified staff, were incorrect or inadequate (12.6\% of cases in the first audit). This system was changed so that all plasters were checked by senior nurses or A\&E registrars because many A\&E SHOs had little prior experience of plastering. A combination of stopping inappropriate doctors checking plasters and increasing accountability radically improved the quality of plasters applied.

There was no improvement in the diagnostic stan- 
D.P. Jenkins et al.

dard and radiograph interpretation between the first and second audits, the rates of missed fracture being 2.8 and $3.6 \%$ respectively. (Radiographs are reviewed the next working day by a radiologist and these figures include any fractures that were seen by radiologists but not noted by A\&E staff.) Anyone with a fracture who did not have a radiograph taken would not be included unless they reattended the A\&E department. However, the Royal College of Radiologists Working Party Report ${ }^{4}$ found that only $0.03 \%$ of new patients attending an A\&E department had a fracture missed because a radiograph was not taken at the initial visit. No change was expected in the missed fracture rates because the guidelines do not deal with diagnosis but with management.

It was found that for $9 \%$ of the patients in the second audit, the fracture clinic appointment time deviated from that suggested in the guidelines. On investigation of these cases it transpired that the deviation had been intended to increase patient convenience or had occurred as a result of full fracture clinics, and no increased morbidity resulted. The guidelines allowed the abandonment of the previous policy which stated that all patients with fractures should be seen the next day.

It is not yet standard to have 24-h senior medical cover in the A\&E department and juniors doctors are not expected to have previous experience in all specialties. In the field of orthopaedics and fracture management juniors doctors may be unaware of local working policies, which can lead to delays and frustrations despite a good basic understanding of the specialty. The implementation of guidelines facilitated the availability of a unified policy. The stipulation in the guidelines that certain conditions must be discussed with an on-call orthopaedic or A\&E registrar prevented many of the errors that occurred when the severity of an injury was not identified and the patient was sent home. The most common cases were distal radius fractures in younger adults being treated in the same way as a Colles' fracture in an elderly person, and the indications for referral of phalangeal fractures. For these reasons it was found that the use of guidelines was helpful and worthwhile even before they were shown to improve management. A further benefit from the audit was the feedback, enabling individual SHOs to get direct confirmation of success and failure.

The audit demonstrated the suitability of guidelines for the management of upper limb fractures and they will continue to be used in the department with updates and refinements taking place as necessary. The study also established that a simple audit form can be used to monitor fracture treatment, and it is suitable for use in any A\&E department.

\section{REFERENCES}

1. Smith T. (1990) Medical audit. British Medical Journal $300,65$.

2. Gardner M.J. \& Altman D.G. (1989) Statistics With Confidence. British Medical Association, London.

3. Department of Health (1990) The Quality of Medical Care. HMSO, London.

4. Royal College of Radiologists (1985) Radiography of injured arms and legs in eight accident and emergency units in England and Wales. British Medical Journal 2, 1325. 